\title{
Does stress cause heart attacks?
}

\author{
M.G. Marmot
}

Department of Community Medicine, University College Hospital and The Middlesex Hospital Medical School, London WCIE 6EA, UK.

\section{Stress or.diet}

A survey conducted by the Health Education Council asked people what they thought was the major cause of heart attacks: $55 \%$ said stress; $24 \%$ said a bad or wrong diet. This has provoked various reactions. One has been: the public, as always, has got it wrong - diet is the major cause and clearly the public have got some notion from unreliable sources which has to be corrected. A second reaction has been: the public has got it right and the experts have it wrong, and no further research is needed to show that stress is the cause.

There are two poles of opinion when it comes to considering stress and heart disease. One is that we have established clear links; both the scientist and the public know that stress is the major cause of heart attacks. The second is that when we, as scientists, consider stress we must conclude that we cannot study it any further. The need is there but since we cannot define stress, we cannot measure it. Stress to one person is stimulus to another and hence by implication, stress does not exist. If the scientists cannot define or measure it, it can be ruled out of discussions on prevention.

To avoid these extreme poles of opinion, stress needs to be brought into the scientific discourse on prevention of coronary disease. Attempts can be made to define it, to measure it, to study it. It can be studied scientifically, and one can attempt to moderate its effects and evaluate those attempts. It is a serious discussion that should take place in a scientific and public health context.

\section{Coronary risk factors - known and unknown}

Such discussion of stress needs to be set in the context of what else we know about the prevention of coronary disease. It is important to avoid the sort of argument where one side claims coronary heart disease (CHD) is all stress-induced and the other side that it is all dietary. It needs to be repeated that coronary

Correspondence: Professor M.G. Marmot, Ph.D., B.Sc., M.B., B.S., M.F.C.M., M.P.H. heart disease is a complex disease that has multifactorial aetiology. It is not difficult to put forward a biological model that emphasizes the importance of the classical risk factors while allowing for the influence of relationships between people and between individuals and the social environment.

Cholesterol, smoking and blood pressure are strongly related to coronary heart disease incidence and mortality. Putting these three risk factors together, Figure 1 shows the striking difference in CHD mortality between a non-smoker, not classified as hypertensive, with low plasma cholesterol $(2.40 / 1000$ in 5 years) and someone high on all three (17.5/1000 in 5

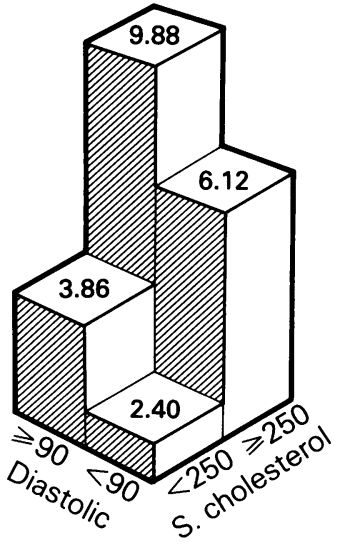

Non-smokers

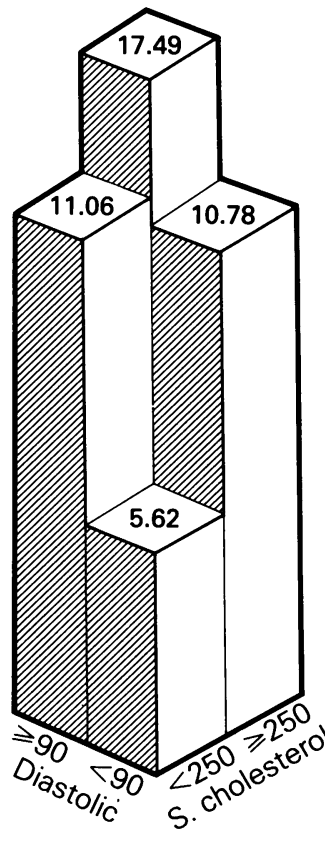

Smokers
Figure 1 Five year CHD death rates per 1,000 in 325,384 white males age $35-57$ who were screened as part of the US Multiple Risk Factor Intervention Trial (Neaton et al., 1984).

(C) The Fellowship of Postgraduate Medicine, 1986 
years) (Neaton et al., 1984). A relative difference of this magnitude argues strongly for causality. In addition, data reviewed by Mann \& Marmot (1983) supports the view that experimental reduction in plasma cholesterol by diet or drugs leads to a concomitant reduction in coronary heart disease (Marmot et al., 1984). The work of Morris (1983) and others points to a possible independent protective effect of vigorous exercise.

It is not necessary to decry the importance of 'established' risk factors to make a case for studying psycho-social factors. Diet, smoking and blood pressure are related to coronary disease and that is the context in which we should proceed. Having said that, there is much about the aetiology of heart disease that we do not understand. Our ten year follow-up of the Whitehall study of civil servants shows that the administrative grades of the civil service have about one third the coronary heart disease mortality of the lowest grade (Figure 2). There is a step-wise relationship: the lower in the civil service the higher the coronary heart disease mortality (Marmot et al., 1984). This can only partly be explained on the basis of the risk factors we know.

There are two points to be made. First, taking the established risk factors: it is not sufficient to say that smoking explains part of the grade difference in coronary heart disease. We must ask why smoking shows a clear social distribution: $20 \%$ of administrators were smokers compared to $61 \%$ of the lowest grade. This social distribution implies that there are

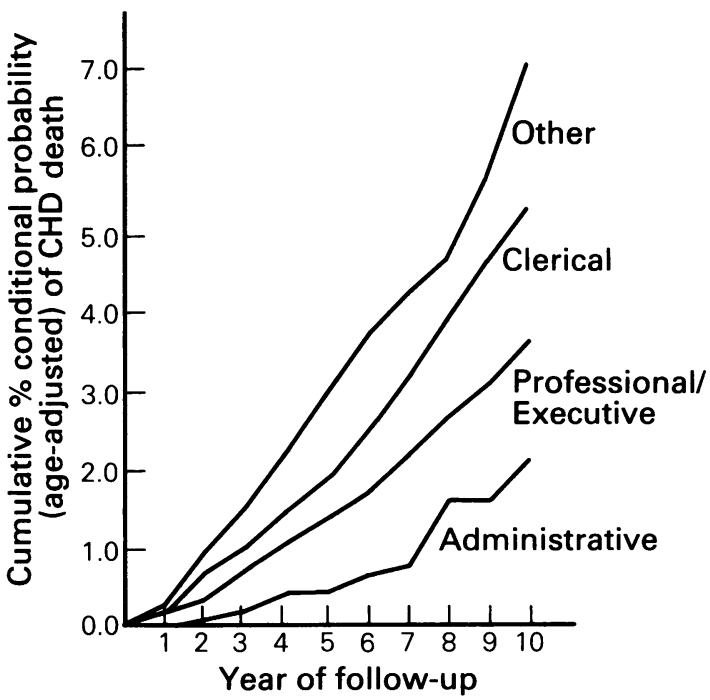

Figure 2 Proportion of men, aged 40-64 at entry, dying in 10 years of follow-up in the Whitehall study of British civil servants. Administrative $=$ highest grade; other = lowest grade (Marmot et al., 1984). social forces acting on people that lead to the decision to smoke - it is not simply an individual decision. Similarly, more of the higher grade men were physically active in their leisure time (37\%) compared to the lowest grade $(14 \%)$. We must ask not only if physical activity is related to coronary disease but why the social distribution exists. What psycho-social factors lead people to be smokers and lead them to be physically active or inactive?

The second point raised by these data is that coronary heart disease is more common in the lower grades even after taking into account the differences in smoking and other risk factors. For example, the Whitehall data make it clear that plasma cholesterol is strongly related to coronary heart disease mortality but knowledge of plasma cholesterol in no way helps us to understand the grade difference in mortality. There are other factors operating that are independent of the amount of fat in the diet. The fact that we need to search for other explanations does not invalidate the importance of plasma cholesterol, smoking or blood pressure.

\section{Psycho-social factors}

Can psycho-social factors be part of the explanation for the graded difference in mortality? The termo 'psycho-social factors' is preferable to the popular idea of 'stress' which centres on the business executive who is busy and rushed, trying to do a hundred and one things. This is akin to Type A behaviour: a model which may be too limited in its social and cultural perspective. For example, among civil servants from the Whitehall study, Type A behaviour is more common in the higher grades, coronary mortality is more common in the lower grades (Marmot, 1984).

1 Low social supports $-----\rightarrow$ III health

or

2 III health $-----\rightarrow \begin{aligned} & \text { Low social } \rightarrow \\ & \text { supports }\end{aligned} \rightarrow$ III

or

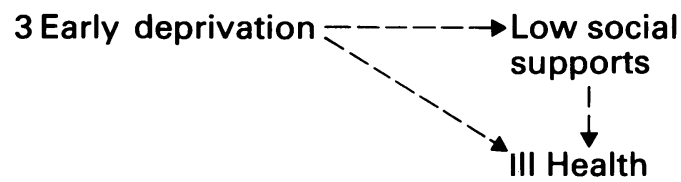

Figure 3 Alternative explanations of an apparent relationship between low social supports and ill health. 
Table I Per cent of men reporting selected psycho-social characteristic according to grade of employment in the British civil service

\begin{tabular}{|c|c|c|c|c|}
\hline Characteristic & Administrative & $\begin{array}{l}\text { Professional } \\
\& \text { executive }\end{array}$ & $\begin{array}{l}\text { Clerical } \\
\text { officers }\end{array}$ & Others \\
\hline \multicolumn{5}{|l|}{ Social supports } \\
\hline See confidant daily & 92 & 86 & 82 & 80 \\
\hline No contact with relatives & 15 & 17 & 20 & 22 \\
\hline No contact with neighbours & 37 & 40 & 55 & 69 \\
\hline No social contact with people at work & 55 & 66 & 72 & 82 \\
\hline No contact with other friends & 20 & 22 & 20 & 40 \\
\hline \multicolumn{5}{|l|}{ Job attitudes } \\
\hline Underuse of skills & 50 & 58 & 68 & 67 \\
\hline Little or no control & 7 & 14 & 18 & 33 \\
\hline Not fair treatment & 11 & 16 & 16 & 33 \\
\hline No variety & 0 & 4 & 21 & 37 \\
\hline Job of little value & 2 & 2 & 6 & 9 \\
\hline \multicolumn{5}{|l|}{ Activities outside work } \\
\hline Involved hobbies - solitary & 46 & 36 & 26 & 20 \\
\hline Organized social-sedentary & 45 & 39 & 30 & 29 \\
\hline Active - not vigorous exercise & 85 & 86 & 62 & 40 \\
\hline Active sports & 39 & 32 & 24 & 33 \\
\hline
\end{tabular}

Type A behaviour, as conventionally defined and measured, will not explain the grade difference in mortality. The notion of stress has been broadened and more effort has been made to define it. There has been much work devoted to the social perspective: unemployment and employment and the interaction between the personal and the social. For example, Table I reproduces data from our civil servants study (Marmot, 1984). It shows that men in lower grades, in general, report fewer social supports, fewer leisuretime activities and more adverse experiences at work than men do in higher grades. We have some evidence that work attitudes may be related to pathogenic pathways to coronary heart disease. We found a difference in plasma fibrinogen between grades (low grade - higher fibrinogen) that was of the order of magnitude that was found in the Northwick Park Heart Study, to distinguish between people who subsequently died of coronary disease and those who did not (Markowe et al., 1985). It suggests the possibility that the lower grade men have a greater propensity to form blood clots and hence higher coronary mortality. Using the variables in Table I, men who have poor job satisfaction have higher plasma fibrinogen and 'job satisfaction' explained about half of the grade difference in fibrinogen (Markowe et al., 1985). This provides a potential link between social and personal circumstances and coronary mortality. As yet, we have not examined the relation between job characteristics and disease in individuals. We are now planning such a study.

I wish to finish on a note of caution. We shall always have enthusiasts who believe in the link between stress and disease no matter what, and sceptics whom we shall never convince. Naïvely, I feel that progress can be made by making our research more rigorous. Our studies need, to the greatest possible extent, to be able to stand up to critical scrutiny in research on psychosocial factors as in other areas. We must consider the quality of our measurements, the quality of our concepts, the possibility of confounding variables, and the causal directions in which variables act in the same way as we must in a study of physical activity, smoking, diet, etc. For example, if there is a relationship between low social support and ill health it could work in a variety of ways (Figure 3 ). Low social supports could lead to ill health: ill health could lead to low social supports and that in turn might exacerbate the process: some common factor such as early deprivations could lead both to low social supports and to ill health. Hence a relationship between low social supports and ill health does not of itself mean that low social supports were responsible for the ill health. Attention to such problems does not necessarily invalidate conclusions but may strengthen them.

I would hope that the outcome of this discussion would be to introduce psycho-social factors into the main discourse about prevention of coronary heart disease. 
References

MANN, J.I. \& MARMOT, M.G. (1983). Epidemiology of ischaemic heart disease. In Oxford Textbook of Medicine, Ledingham, J.G.G., Warrell, D.A. \& Weatherall, D.J. (eds). Oxford University Press: Oxford.

MARKOWE, H.L.J., MARMOT, M.G., SHIPLEY, M.J., BULPITT, C.J., MEADE, T.M., STIRLING, T., VICKERS, M.V. \& SEMMENCE, A. (1985). Fibrinogen: A possible link between social class and coronary heart disease. British. Medical Journal, 291, 1312.

MARMOT, M.G. (1984). Type A behaviour and ischaemic heart disease. In The Spectrum of Psychiatric Research, Shepherd, M. (ed). p. 237. Cambridge University Press: Cambridge.
MARMOT, M.G., SHIPLEY, M.J. \& ROSE, G. (1984). Inequalities in death - specific explanations of a general pattern? Lancet, i, 1003.

MORRIS, J.N. (1983). Exercise, health and medicine. British Medical Journal, i, 1597.

NEATON, J.D., KULLER, L.H., WENTWORTH, D. \& BORHANI, N.O. (1984). Total and cardiovascular mortality in relation to cigarette smoking, serum cholesterol concentration and diastolic blood pressure among black and white males followed up for five years. American Heart Journal, 108, 759. 